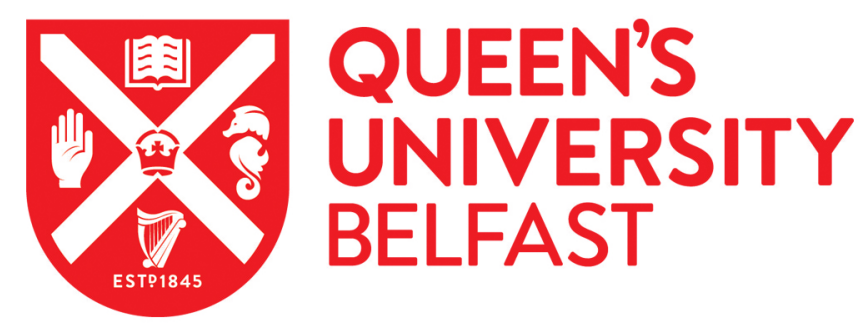

\title{
Comparison of the electron density measurements using Thomson scattering and emission spectroscopy for laser induced breakdown in one atmosphere of helium
}

Nedanovska, E., Nersisyan, G., Morgan, T. J., Hüwel, L., Lewis, C. L. S., Riley, D., \& Graham, W. G. (2011). Comparison of the electron density measurements using Thomson scattering and emission spectroscopy for laser induced breakdown in one atmosphere of helium. Applied Physics Letters, 99(26), [261504]. https://doi.org/10.1063/1.3672817

Published in:

Applied Physics Letters

Document Version:

Publisher's PDF, also known as Version of record

Queen's University Belfast - Research Portal:

Link to publication record in Queen's University Belfast Research Portal

\section{Publisher rights}

Copyright 2011 American Institute of Physics.

This work is made available online in accordance with the publisher's policies. Please refer to any applicable terms of use of the publisher.

\section{General rights}

Copyright for the publications made accessible via the Queen's University Belfast Research Portal is retained by the author(s) and / or other copyright owners and it is a condition of accessing these publications that users recognise and abide by the legal requirements associated with these rights.

Take down policy

The Research Portal is Queen's institutional repository that provides access to Queen's research output. Every effort has been made to ensure that content in the Research Portal does not infringe any person's rights, or applicable UK laws. If you discover content in the

Research Portal that you believe breaches copyright or violates any law, please contact openaccess@qub.ac.uk. 


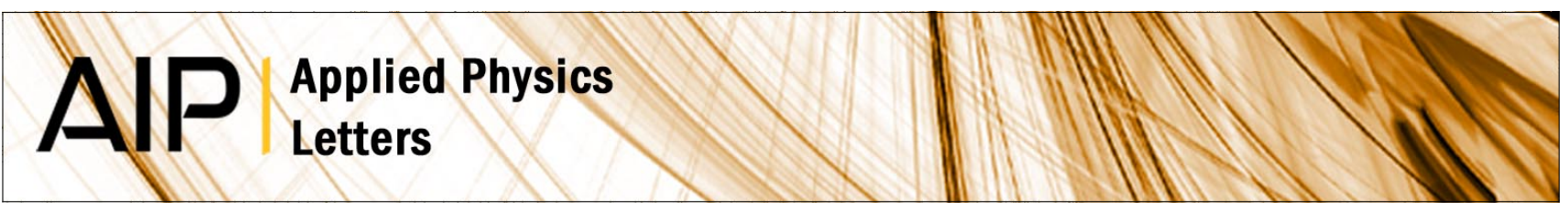

Comparison of the electron density measurements using Thomson scattering and emission spectroscopy for laser induced breakdown in one atmosphere of helium

E. Nedanovska, G. Nersisyan, T. J. Morgan, L. Hüwel, C. L. S. Lewis et al.

Citation: Appl. Phys. Lett. 99, 261504 (2011); doi: 10.1063/1.3672817

View online: http://dx.doi.org/10.1063/1.3672817

View Table of Contents: http://apl.aip.org/resource/1/APPLAB/v99/i26

Published by the American Institute of Physics.

\section{Related Articles}

Microwave scattering from laser spark in air J. Appl. Phys. 112, 063101 (2012)

Optimized laser pulse profile for efficient radiation pressure acceleration of ions

Phys. Plasmas 19, 093112 (2012)

Laser-produced aluminum plasma expansion inside a plastic plasma envelope

Phys. Plasmas 19, 092106 (2012)

Time-resolved soft x-ray spectra from laser-produced Cu plasma

Rev. Sci. Instrum. 83, 10E138 (2012)

Coded aperture imaging of fusion source in a plasma focus operated with pure D2 and a D2-Kr gas admixture Appl. Phys. Lett. 101, 114104 (2012)

\section{Additional information on Appl. Phys. Lett.}

Journal Homepage: http://apl.aip.org/

Journal Information: http://apl.aip.org/about/about_the_journal

Top downloads: http://apl.aip.org/features/most_downloaded

Information for Authors: http://apl.aip.org/authors

\section{ADVERTISEMENT}

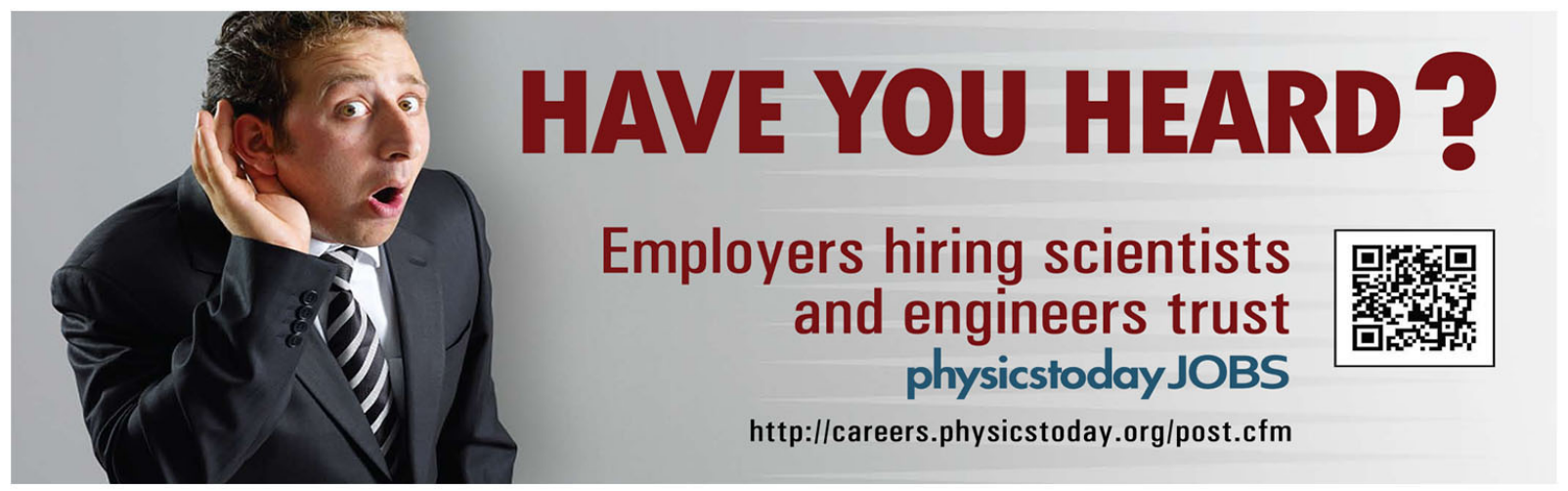




\title{
Comparison of the electron density measurements using Thomson scattering and emission spectroscopy for laser induced breakdown in one atmosphere of helium
}

\author{
E. Nedanovska, ${ }^{1, a)}$ G. Nersisyan, ${ }^{1}$ T. J. Morgan, ${ }^{2}$ L. Hüwel, ${ }^{2}$ C. L. S. Lewis, ${ }^{1}$ D. Riley, ${ }^{1}$ \\ and W. G. Graham ${ }^{1}$ \\ ${ }^{1}$ Department of Physics and Astronomy, Centre for Plasma Physics, Queen's University Belfast, BT71NN, \\ United Kingdom \\ ${ }^{2}$ Department of Physics, Wesleyan University, Middletown, Connecticut 06459, USA
}

(Received 21 October 2011; accepted 6 December 2011; published online 28 December 2011)

\begin{abstract}
Thomson scattering from laser-induced plasma in atmospheric helium was used to obtain temporally and spatially resolved electron temperature and density profiles. Electron density measurements at $5 \mu \mathrm{s}$ after breakdown are compared with those derived from the separation of the allowed and forbidden components of the $447.1 \mathrm{~nm}$ He I line. Plasma is created using $9 \mathrm{~ns}, 140 \mathrm{~mJ}$ pulses from Nd:YAG laser at $1064 \mathrm{~nm}$. Electron densities of $\sim 5 \times 10^{16} \mathrm{~cm}^{-3}$ are in good agreement with Thomson scattering measurements, benchmarking this emission line as a useful diagnostic for high density plasmas. (C) 2011 American Institute of Physics. [doi:10.1063/1.3672817]
\end{abstract}

Laser produced plasmas have found applications in a variety of circumstances, including fast triggering in gaseous environments ${ }^{1}$ and elemental analysis of solid and liquid samples. ${ }^{2}$ In the latter context, the role of the ambient gas in general and that of helium in particular ${ }^{3-5}$ as well as gas dynamic effects ${ }^{6}$ have been the focus of recent studies. The purpose of the current work is to expand on recent experiments ${ }^{7}$ and to demonstrate with the help of Thomson scattering (TS) that certain emission based diagnostic techniques used in these applications are reliable and set the stage for progressing into the low electron density regime $\left(10^{15} \mathrm{~cm}^{-3}\right.$ and below) characteristic of micro-plasmas. Results for the electron density presented in the current paper test the reliability of commonly applied spectroscopic methods, in particular the HeI line at $447.1 \mathrm{~nm}$ which can be used to determine electron density by monitoring the separation and intensity ratio of the allowed $\left(2 \mathrm{p}{ }^{3} \mathrm{P}_{0}-4 \mathrm{~d}^{3} \mathrm{D}\right)$ and forbidden $\left(2 \mathrm{p}^{3} \mathrm{P}_{0}-4 \mathrm{f}^{3} \mathrm{~F}_{0}\right)$ components. Several authors have published equations relating the electron density to the spectral separation and intensity ratio of the allowed and forbidden components of this particular line. ${ }^{8-10}$ It is important that such a diagnostic is tested against an independent measurement. This has been done in discharges for the $447.1 \mathrm{~nm}$ line, for example, using interferometry for densities between (1.9$5.9) \times 10^{15} \mathrm{~cm}^{-3}$ (Ref. 11) and between $(1-7) \times 10^{17} \mathrm{~cm}^{-3} \cdot{ }^{9}$ Both experiments were performed without spatial resolution along the axis of low pressure pulsed discharges. In the current work, we have employed Thomson scattering to obtain both temporally (20 ns window) and spatially $(6.9 \mathrm{~mm})$ resolved electron temperature and electron density profiles to make a direct comparison with electron density measurements derived from emission spectroscopy (ES). In particular, we present an assessment of the HeI $447.1 \mathrm{~nm}$ methods for the intermediate range of $(1-5) \times 10^{16} \mathrm{~cm}^{-3}$ in atmospheric pressure laser produced plasmas.

\footnotetext{
${ }^{\text {a) }}$ Author to whom correspondence should be addressed. Electronic mail: enedanovska01@qub.ac.uk.
}

Our experimental arrangement is shown schematically in Fig. 1. A vacuum chamber is evacuated to approximately $10^{-4}$ mbar and backfilled to $1 \mathrm{~atm}$ with He. Using a $10 \mathrm{~cm}$ focal length lens, a $9 \mathrm{~ns} 140 \mathrm{~mJ}$ pulse from an $\mathrm{Nd}$ :YAG laser (GCR 4) with an initial spot diameter of $\sim 9 \mathrm{~mm}$ is focused into the chamber centre by a lens of f/12.5. The baffle arms are fitted with Brewster angle windows to reduce stray light scattering. Light emitted from the induced plasma at $90^{\circ}$ to the direction of the breakdown beam is collected with an $f / 5$ lens, and a second lens is used to image the plasma with unity magnification onto the slit of an imaging double grating spectrometer (SPEX 750, with $12001 / \mathrm{mm}$ gratings providing $5.7 \AA / \mathrm{mm}$ at the detector plane). The diverging beam, transmitted through the helium, exits the chamber via a BK7 window and into a light trap. The spectrometer provides spatial resolution in the direction perpendicular to the direction of the breakdown beam (lateral direction). The $100 \mu \mathrm{m}$ slit provides effective spatial resolution along the axial direction. For Thomson scattering, a separate laser is used $(7 \mathrm{~ns}, 80 \mathrm{~mJ}$ at $532 \mathrm{~nm}$ ). This beam is directed perpendicular to the

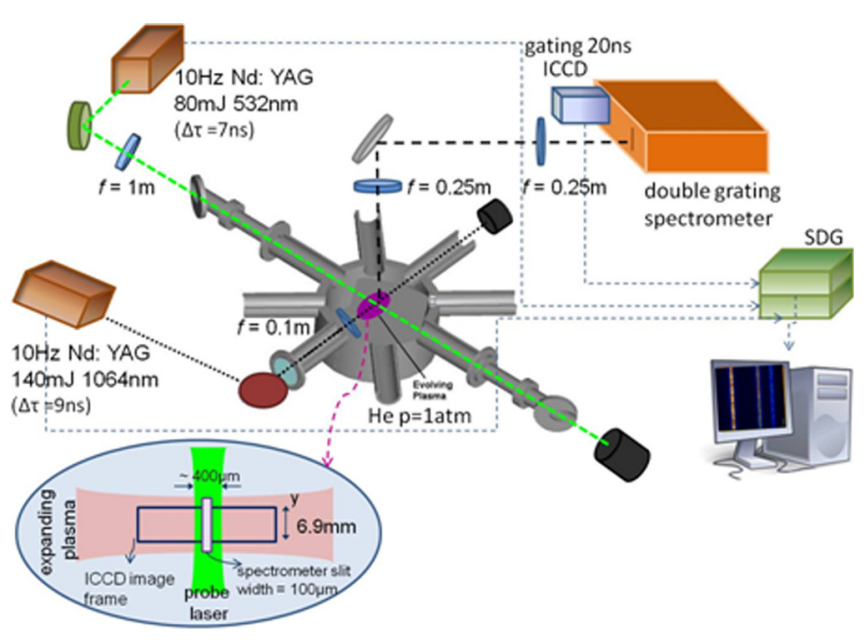

FIG. 1. (Color online) Schematic of set-up for Thomson scattering. 

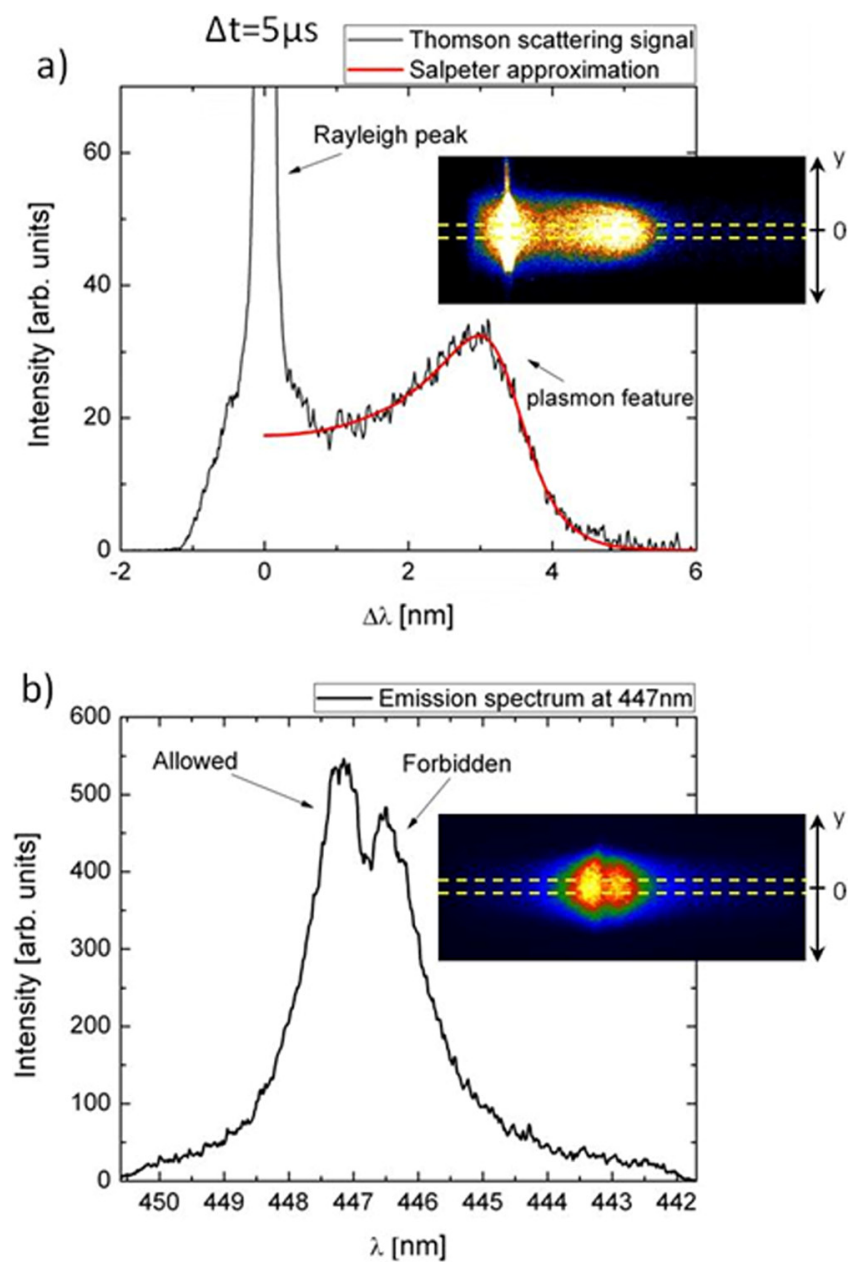

FIG. 2. (Color online) Typical data for $5 \mu$ s delay: (a) Thomson scattering and (b) emission spectroscopy. The upshifted, blue wing of the Thomson scattering is fitted to the Salpeter approximation. The image insets show the spatial region over which the line-outs are averaged.

breakdown pulse, and so the Thomson scattered signal on the spectrometer slit provides lateral resolution. The probe pulse is loosely focused with a full width half maximum of approximately $400 \mu \mathrm{m}$ in order to avoid heating by the probe. The spectrometer was fitted with an intensified CCD camera that was gated to $20 \mathrm{~ns}$ for both Thomson scattering and emission spectroscopy. The two lasers and the CCD were synchronized using a Stanford Delay Generator (SDG). The system was calibrated by filling the chamber with 10 mbar of Argon and measuring the Rayleigh intensity. ${ }^{12}$

In Fig. 2(a), we show typical Thomson scattering data and a spectral line-out of the central $0.54 \mathrm{~mm}$ of the breakdown at $5 \mu$ s delay. In Fig. 2(b), a sample emission spectrum of the $447.1 \mathrm{~nm}$ line for the same conditions is shown. As can be seen, at this time, the Thomson scattering is in the collective regime which manifests with a plasmon feature in the spectrum, and fitting to the Salpeter approximation ${ }^{13}$ yields both density and temperature.

By $5 \mu \mathrm{s}$, the plasma has expanded up to $\approx 4.3 \mathrm{~mm}$ in the direction parallel to the probing laser beam (y axis); later in time, it develops a "torus" structure probably as a result of radially propagating shock formation, ${ }^{14}$ and the Thomson scattering moves into non-collective mode. Here, we use the lowest electron density where the plasma is uniform, at the early time of $5 \mu \mathrm{s}$, to compare emission and scatter data. In

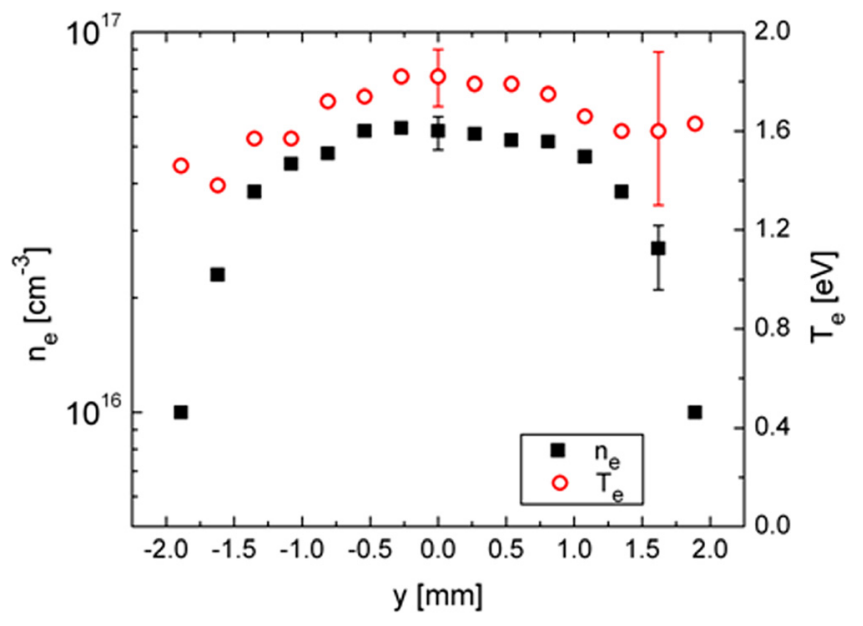

FIG. 3. (Color online) Electron density and temperature lateral profile (y axis) for $5 \mu$ s delay from the Thomson scattering signal. The uncertainties for the density and temperature are within $13 \%$ and $10 \%$, respectively, for $|\mathrm{y}|<1.5 \mathrm{~mm}$ and within $22 \%$ and $20 \%$ for $|\mathrm{y}|>1.5 \mathrm{~mm}$. The experimental data have reproducibility of $95 \%$.

Fig. 3, we show the lateral profiles of the electron temperature and density at this time delay deduced from the Thomson scattering signal, and the uniformity of the plasma is evident, apart from the elevated electron temperature at the extreme edges. The latter is possibly an artifact from the initial blast wave. ${ }^{14}$

The emission spectra, although resolved spatially in the direction of the probe laser, originate from a line of sight through the plasma, and Abel inversion is needed. By assuming cylindrical symmetry of the induced plasma, we can Abel invert the signal to obtain the radial intensity profile. For the Thomson scattering, Abel inversion is not needed since we do not scatter through a line of sight through the plasma but from a limited region defined by the $0.4 \mathrm{~mm}$ probe beam diameter, which is small compared to the $\approx 4.3 \mathrm{~mm}$ diameter of the plasma at this stage of its evolution. Aside from the cylindrical symmetry of the plasmas, the other main assumption for the Abel inversion is low optical density of the plasma. A rough analysis of the Rayleigh peak, at the central $0.54 \mathrm{~mm}$ of the plasma region, assuming only the presence of He neutral atoms and $\mathrm{HeII}$ in the plasma region, yields $\mathrm{He}$ atom density of the order of $4.8 \times 10^{18} \mathrm{~cm}^{-3}$. This value enables us to set an upper limit on the opacity at $\tau=0.1$. In He plasmas, ${ }^{15}$ He metastable $\left(\mathrm{He}\left(2{ }^{3} \mathrm{~S}\right)\right)$, positively charged molecular helium ions $\left(\mathrm{He}_{2}^{+}\right)$, as well as excited molecular helium $\left(\mathrm{He}_{2}^{*}\right)$ are being created. The presence of the aforementioned species can only lead to lowering the density of $\mathrm{He}$ atoms which in turn results in lower opacity of the plasma.

In Fig. 4(a), we show the radially resolved profiles of electron density inferred from the emission data and from Thomson scattering. We have used three different formulae to determine the density from the separation of the allowed and forbidden lines, i.e., those of Perez et al., ${ }^{8}$ Ivković et al., ${ }^{9}$ and Czernichowski and Chapelle ${ }^{10}$ and one formula that uses the forbidden to allowed line ratio $(\mathrm{F} / \mathrm{A}) .{ }^{10} \mathrm{We}$ have used two separate Abel inversion routines, a numerical integration ${ }^{16}$ and the Nestor Olsen approach, ${ }^{17}$ and get consistent results. The degree of agreement of the electron density data from the emission spectroscopy methods with the 


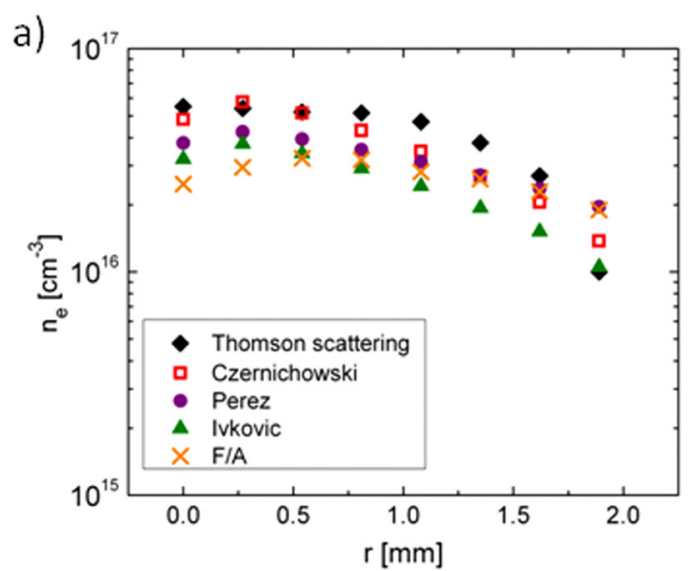

b)

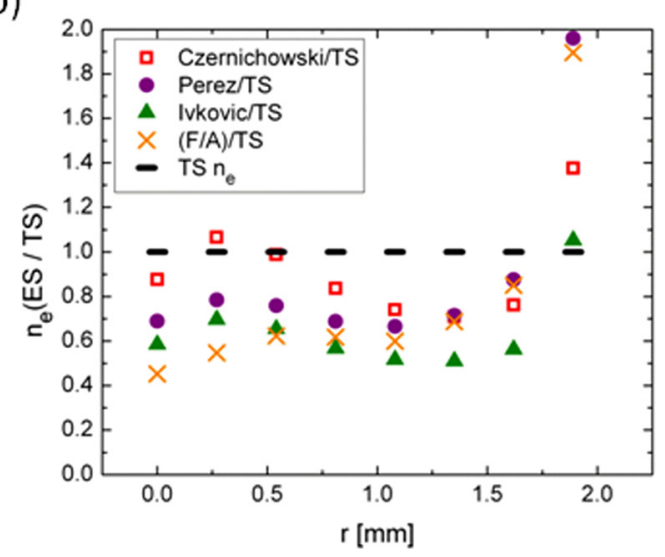

FIG. 4. (Color online) (a) Comparison of electron density, at different radial positions $r$, from the $447 \mathrm{~nm}$ line forbidden-allowed separation methods and intensity ratio (F/A) method with TS data. (b) Ratio of the electron densities from the ES approaches and the TS, after performing Abel inversion. The dashed line represents the Thomson scattering data (TS/TS).

Thomson scattering measurements, in radial direction $r$, is shown in Fig. 4(b). We can see that the empirical formula by Czernichowski and Chapelle ${ }^{10}$ for the forbidden-allowed separation, in particular, agrees very well with the Thomson scattering data. Thus, this emission methodology, for the $447 \mathrm{~nm}$ line at atmospheric pressure, can be used in the density region of $1-5 \times 10^{16} \mathrm{~cm}^{-3}$ with $30 \%$ confidence, and consequently, we have expanded the prescribed validity range in their paper to higher electron densities. The $447 \mathrm{~nm}$ line shapes before and after performing Abel inversion are identical, confirming its homogeneous profile.
To conclude, in the electron density range of (1-5) $\times 10^{16} \mathrm{~cm}^{-3}$, we have used optical Thomson scattering as an independent check on the validity of three formulae that give electron density from the allowed-forbidden component separation in the $447 \mathrm{~nm}$ line of helium and one that is based on the intensity ratio of the forbidden and allowed line. We find in the present electron density regime that there is a better agreement with the line separation than the line ratio method, with the best agreement from the Czernichowski and Chapelle approach. This is an important check as there are many plasma types where diagnostics other than emission spectroscopy are difficult to implement. The open geometry used in our experiment has allowed us to make the comparison. We are now in a position to compare the various emission based techniques with the Thomson scattering in laser-initiated plasma at later times, in the presence of other gases and at electron density regimes believed to be present in electrically produced microplasmas.

E.N. was supported by a Queen's University of Belfast overseas research student award.

${ }^{1}$ H. Sobral and A. Robledo-Martinez, IEEE Trans. Plasma Sci. 36, 4 (2008).

${ }^{2}$ D. W. Hahn and N. Omenetto, Appl. Spectrosc. 64, 335A (2010).

${ }^{3}$ C. A. Henry, P. K. Diwakar, and D. W. Hahn, Spectrochim. Acta, Part B 62, 1390 (2007).

${ }^{4}$ M. Pardede, T. J. Lie, K. H. Kurniawan, H. Niki, K. Fukumoto, T. Maruyama, K. Kagawa, and M. O. Tjia, J. Appl. Phys. 106, 063303 (2009).

${ }^{5}$ K. F. Al-Shboul, S. S. Harilal, A. Hassanein, and M. Polek, J. Appl. Phys. 109, 053302 (2011).

${ }^{6}$ K. F. Al-Shboul, S. S. Harilal, and A. Hassanein, Appl. Phys. Lett. 99, 131506 (2011).

${ }^{7}$ S. K. Monfared, W. G. Graham, T. J. Morgan, and L. Hüwel, Plasma Sources Sci. Technol. 20, 035001 (2011).

${ }^{8}$ C. Perez, I. delaRosa, J. A. Aparicio, S. Mar, and M. A. Gigosos, Jpn. J. Appl. Phys. 35, 4073 (1996).

${ }^{9}$ M. Ivković, M. A. Gonzalez, S. Jovićević, M. A. Gigosos, and N. Konjević, Spectrochim. Acta, Part B 65, 234 (2010).

${ }^{10}$ A. Czernichowski and J. Chapelle, J. Quant. Spectrosc. Radiat. Transf. 33, 427 (1985).

${ }^{11}$ Z. Mijatović, R. Kobilarov, S. Djurović, and M. Stevanov, Appl. Spectrosc. 51, 396 (1997).

${ }^{12}$ M. Sneep and W. Ubachs, J. Quant. Spectrosc. Radiat. Transf. 92, 293 (2005).

${ }^{13}$ E. Salpeter, Phys. Rev. 120, 1528 (1960),

${ }^{14}$ D. Nassif and L. Hüwel, J. Appl. Phys. 87, 2127 (2000).

${ }^{15}$ T. Murakami, E. Nedanovska, D. Riley, and W G. Graham, "Chemical kinetics of a laser-induced breakdown in atmospheric helium," Appl. Phys. Lett. (submitted).

${ }^{16} \mathrm{H}$. R. Griem, Principles of Plasma Spectroscopy (Cambridge University Press, Cambridge, USA, 2005).

${ }^{17}$ O. H. Nestor and H. N. Olsen, SIAM Rev. 2, 3 (1960). 